\title{
Effects of outdoor temperature on the natural smoke extraction strategy in an atrium
}

\author{
Zhen Lanlan' ${ }^{1,2, a}$, Ran Feng ${ }^{1, b}$ \\ ${ }^{1}$ School of Mechatronic Engineering and Automation, Shanghai University, Shanghai, 20072, China \\ ${ }^{2}$ School of Automation Engineering, Shanghai University of Electric Power, Shanghai, 200090, \\ China \\ aemail: zhenlanlan@shiep.edu.cn, ${ }^{b}$ email: ranfeng@shu.edu.cn
}

Keywords: Outdoor temperature; Fire; Natural smoke extraction; Atrium

\begin{abstract}
Natural smoke extraction strategy in an atrium connecting a subway station and commercial building is numerically studied in this article. Different outdoor temperatures ranged from $-10^{\circ} \mathrm{C}$ to $35^{\circ} \mathrm{C}$ during the fire-induced smoke development in the atrium are studied in detail. The t-square fire curve is assumed and the time averaged from 300s to 350s is adopted for quantitative comparisons of visibility and temperature profiles after HRR reaches the maximum 4MW. It is shown from the simulation results that the natural smoke extraction scheme is effective in the range of outdoor temperature from $35^{\circ} \mathrm{C}$ to $25^{\circ} \mathrm{C}$. When the outdoor temperature decreases to $20^{\circ} \mathrm{C}$, the effect of natural smoke extraction is less significant. After further decreasing to $10^{\circ} \mathrm{C}$ or lower, the natural smoke extraction scheme does not work anymore.
\end{abstract}

\section{Introduction}

With the acceleration of urbanization in the world, the integrative design of the commercial or residential building and public transportation arouse great interests due to the high-efficiency of land use and building functions. The term of Transit-Oriented Development (TOD) is used to define such form. It is a mixed-use residential and commercial area designed to maximize access to public transportation, and often incorporates features to encourage transit ridership.

In the integrative building, the pedestrian is normally crowed and fire-induced smoke will cause huge casualties and property loss once fire happens. In the fire, studies proved that smoke is the main cause of death [1]. In the past two decades, many researchers used the Computational Fluid Dynamics (CFD) technology to investigate the smoke control strategies during the atrium fire. Hadjisophocleous and Lougheed [2] carried out the full-scale experiment and numerical simulation to investigate the atrium smoke exhaust phenomena. A comparison between the experimental and predicted temperatures and $\mathrm{CO}_{2}$ concentrations verified that the CFD model can predict the conditions in the room, as well as the depth of the hot layer. Chew and Liew [3] employed a CFD model based on PHOENICS to predict the distribution of fire-induced air flow, temperature and smoke concentration in an atrium. Chow and Li [4] studied the smoke-filling process in atria of local shopping malls. Chang et al. [5] numerically simulated the effect of natural venting opening in ceiling, mechanical exhaust and hanging porous curtains across the ceiling by zone-based and field-based models for the case that one building with an atrium got fire. Yi et al. [6] studied the effect of different positions of make-up air supply on the performance of a mechanical exhaust system in an atrium by the zone model. Shi et al. [7] carried out a detailed study for the smoke movement and spill plume development in a full-scale atrium due to a retail shop fire. Ji et al. [8] numerically investigated the buoyancy-driven natural ventilation flows in a single-storey space connected to an atrium. Chow and $\mathrm{Li}$ [9] discussed the bidirectional flow across a ceiling vent in an atrium on the smoke layer interface height for the purpose of fire defects in a typical atrium. Wang et al. [10] recommended using smoke screen and mechanical exhaust facilities to achieve virtual fire district. Tilley and Merci [11] presented an extensive numerical study to consider the fire heat release rate (HRR), extraction mass flow rate, position of the extraction device or opening and the size and position of openings in an atrium fire. $\mathrm{Xu}$ et al. [12] numerically studied the factors of the 
smoke removal efficiency including smoke evacuation quantity, atrium shape coefficient, smoke exhaust fan start-up time and heat release rate. Qin et al. [13] studied the effects of the roof windows of six different positions to the natural smoke extraction in an atrium fire. Cándido et al. [14] studied the results of natural smoke extractions under three different heat release rate. Gao et al. [15] numerically investigated the hybrid ventilation for fire-induced smoke control in an atrium of a large transit terminal subway station.

Basically, the adoption of natural smoke extraction strategy in large-space atria is significantly influenced by the outdoor environment like wind speed and direction, and outdoor temperature. In the worst outdoor conditions, the natural smoke extraction strategy may not work; the smoke cannot be exhausted from the atrium and will cause huge casualties and property loss. In this article, numerical simulations of natural smoke control in an atrium are carried out to study the effects of outdoor temperature. The tenable environment concept [16] will be adopted in this work.

\section{Mathematical model}

Figure 1 shows the physical model that an atrium connects the subway station with a two-storey commercial building. Passengers enter the atrium from the subway station through security gates and go shopping in the commercial district. The schematic diagram of the vertical sectional view is shown in Figure 2. The middle atrium is $51.2 \mathrm{~m}$ in length, $30.6 \mathrm{~m}$ in width and $10 \mathrm{~m}$ in height. The size of two roof windows is $4 \mathrm{~m} \times 4 \mathrm{~m}$ on the top of the atrium. When fire happens in the atrium, roof windows will be opened to exhaust the fire-induced smoke due to the buoyancy force, i.e., the smoke control strategy in the atrium is natural ventilation. The surrounding smoke barrier height is $2.2 \mathrm{~m}$ above the second floor. With atrium walls they form a smoke reservoir that the fire-induced smoke is confined and can be naturally exhausted to outside through two top open windows (see Fig. 2). One criterion of the effective smoke control strategy in the atrium is that the accumulated fire-induced smoke in the smoke reservoir cannot fall below the smoke barrier, or passengers will be exposed to the noxious smoke.

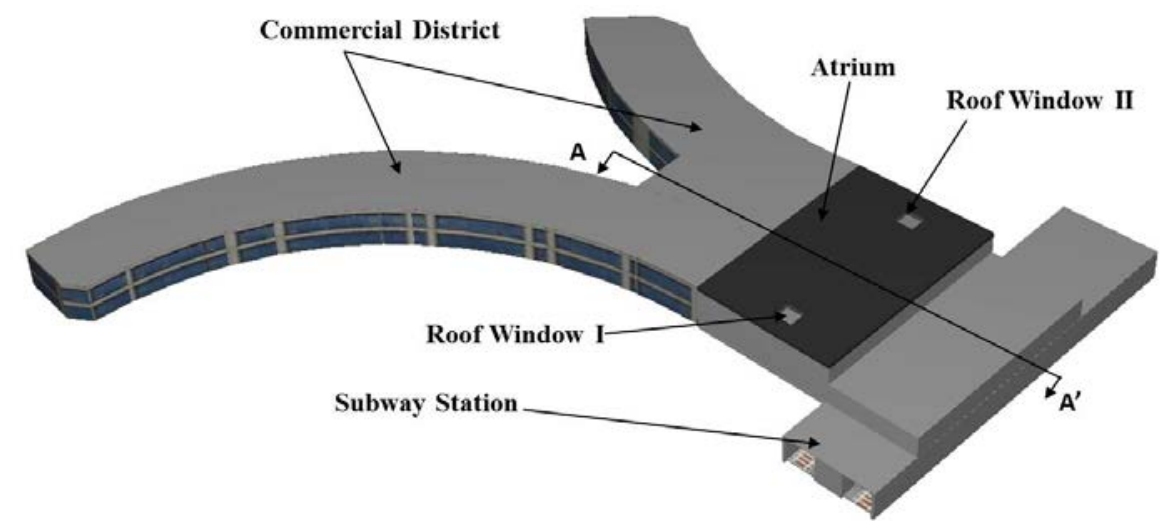

Fig. 1 Physical model
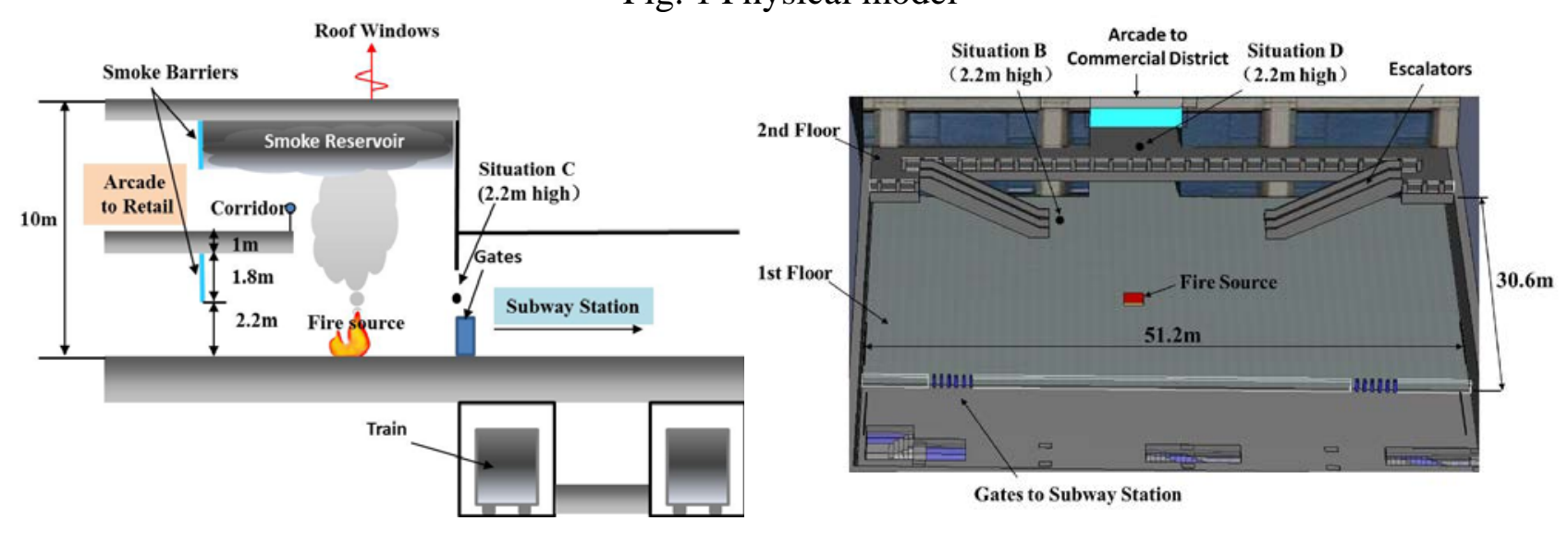

Fig. 2 Internal schemic of physical model

The Fire Dynamic Simulator (FDS), developed by the National Institute of Standards and 
Technology (NIST), is adopted for the numerical simulation work. The governing equations include the conservation equations for mass, momentum and energy, and can be written as follows [17]:

$$
\begin{aligned}
& \frac{\partial \rho}{\partial t}+\nabla \cdot \rho \boldsymbol{u}=\mathbf{0} \\
& \frac{\partial}{\partial t}(\rho \boldsymbol{u})+\nabla \cdot \rho \mathbf{u} \boldsymbol{u}+\nabla \rho=\rho g+f_{b}+\nabla \cdot \tau_{i j} \\
& \frac{\partial}{\partial t}\left(\rho h_{s}\right)+\nabla \cdot \rho h_{s} \mathbf{u}=\frac{D p}{D t}+\dot{q}^{\prime \prime \prime}-\dot{q}_{b}^{\prime \prime \prime}-\nabla \cdot \dot{\boldsymbol{q}}^{\prime \prime}+\varepsilon
\end{aligned}
$$

where $h_{s}$ is enthalpy, $\dot{q}^{\prime \prime \prime}$ is heat release rate per unit volume, $\dot{q}^{\prime \prime}$ is heat flux vector, $\dot{q}_{b}^{\prime \prime \prime}$ is the energy transferred to the evaporating droplets, and $\varepsilon$ is dissipation rate.

The most distinguishing feature in CFD models is the treatment of turbulent flows. Currently, three main methods for fire-induce smoke transportation simulation are Direct Numerical Simulation (DNS), Reynolds-Averaged Navier-Stokes (RANS), and Large Eddy Simulation (LES). DNS needs numerous computational resources and can hardly be handled by personal computers, or even working stations. RANS method is most widely used as it can provide reasonable results. Compared with RANS, LES is better for the predictions of instantaneous turbulent flows like fire-induced turbulent flow [18] and is adopted in FDS code. In LES, the approximate expression modeling the dissipative impacts on the governing equations is proposed by Smagorinsky [19] and the dynamic viscosity $\mu$ is modeled as:

$$
\mu_{L E S}=\rho\left(C_{S} \Delta\right)^{2}\left(2 \bar{S}_{i j}: \bar{S}_{i j}-\frac{2}{3}(\nabla \cdot \bar{u})^{2}\right)^{\frac{1}{2}}
$$

where Cs is an empirical constant and taken as 0.2 [20]. $\Delta$ is a length on the order of the size of a grid cell. The thermal conductivity and material diffusivity are related to the turbulent viscosity [21] by

$$
k_{L E S}=\frac{\mu_{L E S} c_{p}}{\operatorname{Pr}_{t}} ; \quad(\rho D)_{l, L E S}=\frac{\mu_{L E S}}{S c_{t}}
$$

The turbulent Prandtl number $P r_{t}$ and turbulent Schmidt number $S c_{t}$ are assumed to be constant for a given scenario and taken to be 0.2 and 0.5 , respectively [15].

The combustion model used in FDS is based on the mixture fraction combustion model. In combustion, the mixture fraction is a conserved quantity traditionally defined as the mass fraction of the gas mixture that originates in the fuel stream. The mixture fraction, $\mathrm{Z}$, is decomposed into three components:

$$
\begin{aligned}
& Z_{1}=\frac{Y_{F}}{Y_{F}^{I}} \\
& Z_{2}=\frac{W_{F}}{\left[x-\left(1-X_{H}\right) v_{S}\right] W_{C O}} \frac{Y_{C O}}{Y_{F}^{I}} \\
& Z_{3}=\frac{W_{F}}{\left[x-\left(1-X_{H}\right) v_{S}\right] W_{C_{2}}} \frac{Y_{C_{2}}}{Y_{F}^{I}}
\end{aligned}
$$

where $Y_{F}^{I}$ is fuel mass fraction at the fire source surface and $\mathrm{x}$ is the number of carbon atoms in the fuel molecule. $W_{F}$ is the molecular mass of the fuel, $W_{C O}$ is the molecular mass of $\mathrm{CO}, \mathrm{W}_{\mathrm{CO} 2}$ is the molecular mass of $\mathrm{CO}_{2}, X_{H}$ is the hydrogen atomic fraction of the fuel, $v_{\mathrm{s}}$ is the amount of fuel that is converted to soot. $x-\left(1-X_{H}\right) v_{S}$ represents the number of carbon atoms in the fuel molecule that are oxidized, i.e., the carbon atoms that are not converted to soot. In this model, the yields of soot is treated as a constant as 0.028 . It is found that the species concentration predicted by FDS agrees well with the experimental data [22].

In this model, the heat release rate (HRR) is first set to be 4MW and a fast-type fire is used in the study. When the t-square fire is adopted, the time for HRR to grow to $4 \mathrm{MW}$ is 297.73 seconds. Based on the worse scenario assumption, the fire size is kept constant at 4MW after 297.73s, i.e., 
the fire decay phase is not considered.

The material of the wall is concrete and the density, conductivity and specific heat are $2200 \mathrm{~kg} / \mathrm{m}^{3}, 1.2 \mathrm{~W} /(\mathrm{m} \cdot \mathrm{k})$ and $0.88 \mathrm{~kJ} /(\mathrm{kg} \cdot \mathrm{K})$, respectively [15]. The boundary condition for the entrances is set to be OPEN, i.e., air can be free to go inside or outside. The temperature in the atrium is assumed to be constant as $25^{\circ} \mathrm{C}$. Outside environment is assumed to be windless and only outside temperature changes in the model to inspect the influence on the natural smoke control strategy in the atrium.

To ensure the accuracy of the numerical simulation, the grid sensitivity was first checked by a series of grids of $0.15 \mathrm{~m} \times 0.15 \mathrm{~m} \times 0.15 \mathrm{~m}, 0.2 \mathrm{~m} \times 0.2 \mathrm{~m} \times 0.2 \mathrm{~m}, 0.3 \mathrm{~m} \times 0.3 \mathrm{~m} \times 0.3 \mathrm{~m}$ and $0.4 \mathrm{~m} \times$ $0.4 \mathrm{~m} \times 0.4 \mathrm{~m}$, respectively. Table 1 summaries the detailed grid systems used for the grid sensitivity study. The characteristic of entrainment vortex is adopted for the evaluation of the results at different grid systems and the detailed results are presented in Figure 3. It is observed that the predicted results in grid systems $\mathrm{C}$ and $\mathrm{D}$ are almost the same, though the cell number of grid system $\mathrm{D}$ is much larger than grid system $\mathrm{C}$. As grid system $\mathrm{C}$ can ensure simulation accuracy and consume less computing time, the grid size of $0.2 \mathrm{~m} \times 0.2 \mathrm{~m} \times 0.2 \mathrm{~m}$ is used for the simulation.
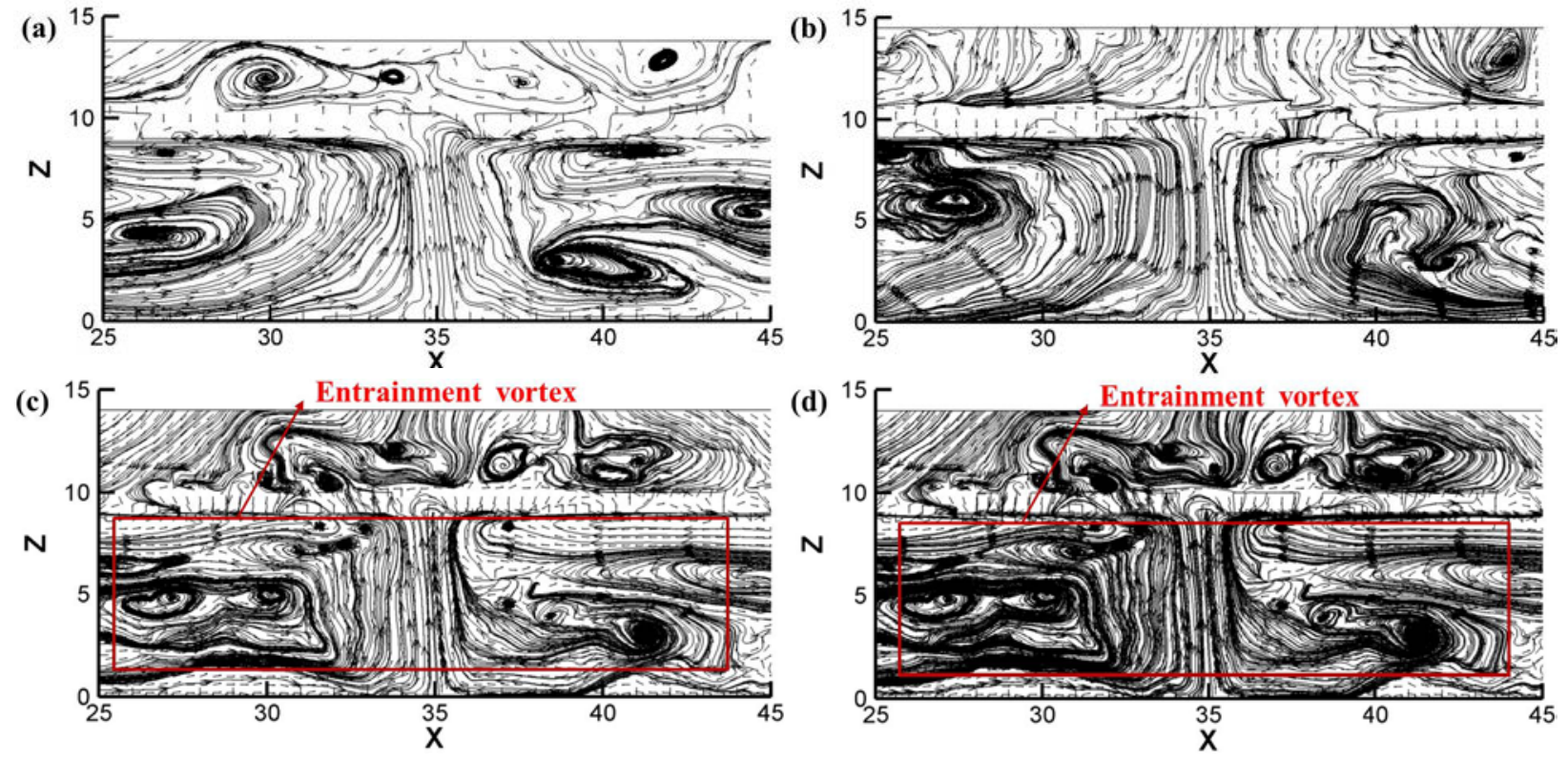

Fig. 3 Velocity vectors predicted at the plume region:(a) $0.4 \mathrm{~m} \times 0.4 \mathrm{~m} \times 0.4 \mathrm{~m}$;(b) $0.3 \mathrm{~m} \times 0.3 \mathrm{~m}$ $\times 0.3 \mathrm{~m}$;(c) $0.2 \mathrm{~m} \times 0.2 \mathrm{~m} \times 0.2 \mathrm{~m}$;(d) $0.15 \mathrm{~m} \times 0.15 \mathrm{~m} \times 0.15 \mathrm{~m}$

\section{Results and Discussion}

Ten outdoor temperatures are selected for simulations: $-10^{\circ} \mathrm{C},-5^{\circ} \mathrm{C}, 0^{\circ} \mathrm{C}, 5^{\circ} \mathrm{C}, 10^{\circ} \mathrm{C}, 15^{\circ} \mathrm{C}, 20^{\circ} \mathrm{C}$, $25^{\circ} \mathrm{C}, 30^{\circ} \mathrm{C}$ and $35^{\circ} \mathrm{C}$. The smoke clear height above the arcade is $2.2 \mathrm{~m}$ to ensure the tenable environment in the occupied zone, i.e., below $2.2 \mathrm{~m}$ height, is acceptable for pedestrian safety. The visibility requirement in the occupied zone is no less than $10 \mathrm{~m}$ [16].

Since the fire-induced smoke development is instantaneous, the time averaged from 300s to 350s is adopted for quantitative comparisons of visibility and temperature profiles after the HRR reaches the maximum to ensure the reasonable results. Figure 4 presents the simulation results of visibility at the vertical section of AA' (see Fig. 1). It is indicated that the visibility in the occupied zone is larger than $10 \mathrm{~m}$ when outdoor temperature decreases from $35^{\circ} \mathrm{C}$ to $25^{\circ} \mathrm{C}$. The tenable environment in the arcade is acceptable for safe evacuation of pedestrians. At the outdoor temperature of $20^{\circ} \mathrm{C}$, the fire-induced smoke disperses to the neighbor smoke zone, however, the visibility in the occupied zone is still acceptable. With the outdoor temperature further decrease to $15^{\circ} \mathrm{C}$, more smoke disperses to the arcade zone of the second floor and the visibility level below $2.2 \mathrm{~m}$ is not fully acceptable, i.e., the natural smoke control scheme partially loses its effectiveness. The situation becomes worse at outdoor temperature of $10^{\circ} \mathrm{C}$ as the fire-induced smoke is quickly 
cooled by outdoor air and more smoke accumulates on the second floor of the commercial district. When the outdoor temperature falls to $5^{\circ} \mathrm{C}$ or lower, more smoke is stored in the atrium due to the large temperature difference between the inside and outside of the atrium. Large temperature difference weakens the upward buoyancy-driven force. Thus, less smoke spreads to the arcade zone of the second floor and the visibility level below the height of $2.2 \mathrm{~m}$ is still larger than $10 \mathrm{~m}$, which is acceptable for safe evacuation pedestrians from the view of the tenable environment.

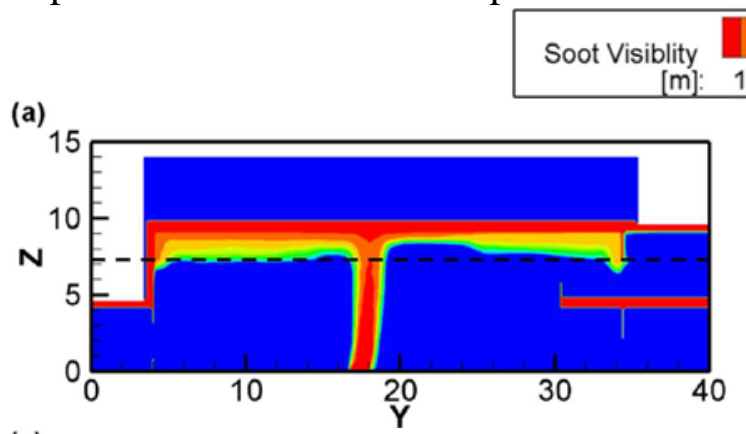

(c)

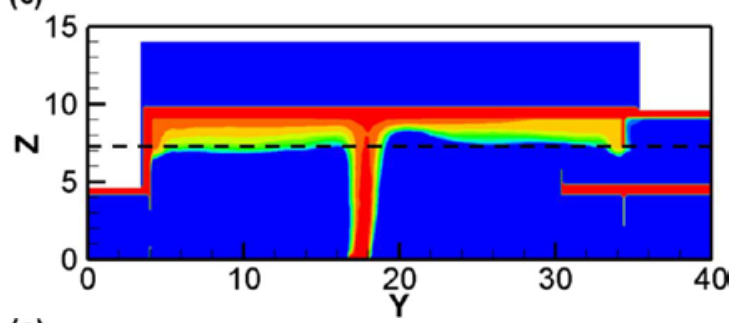

(e)
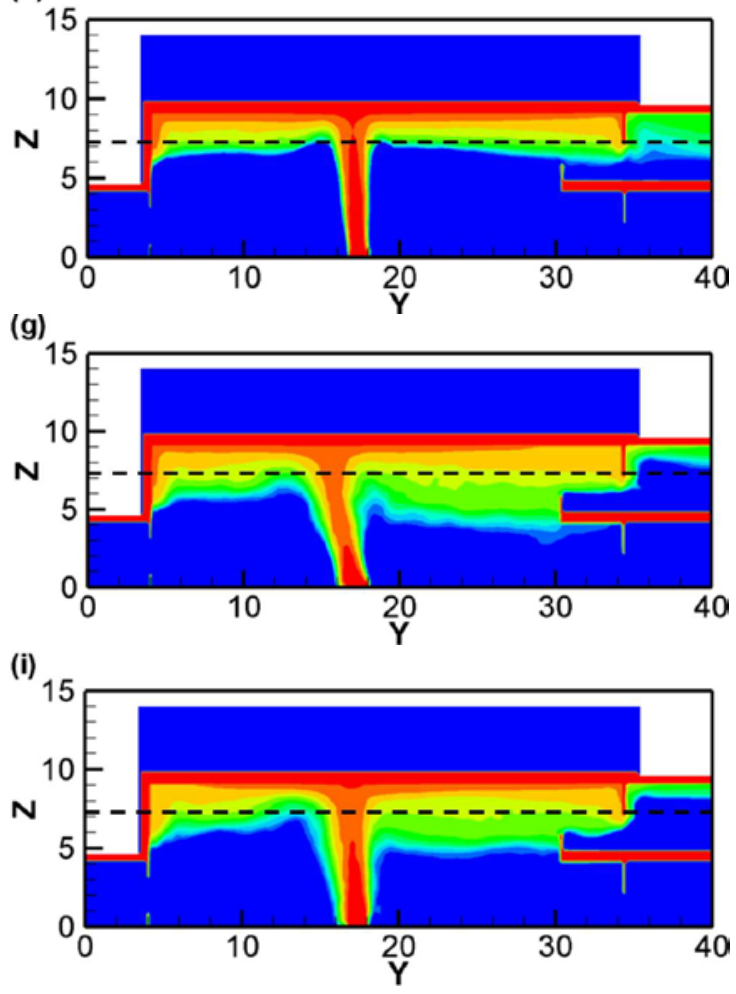

(b)

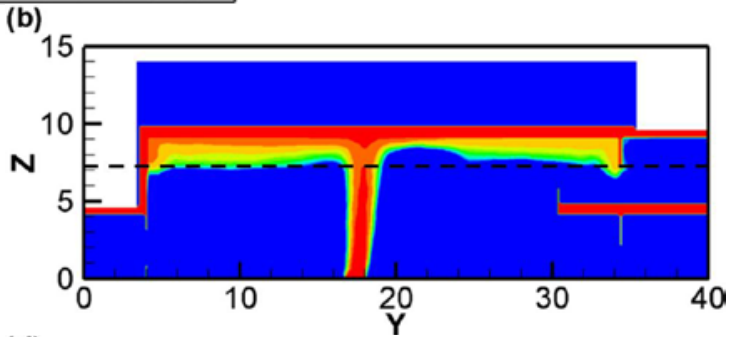

(d)

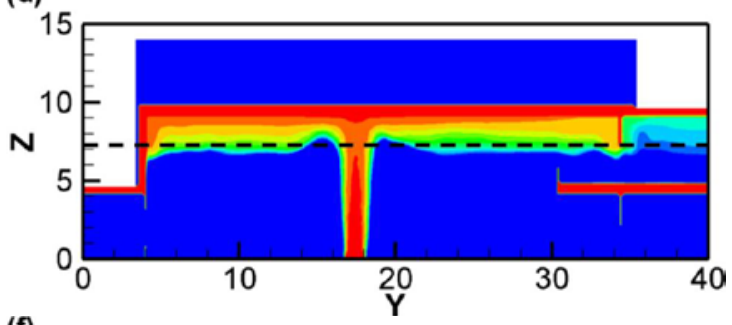

(f)

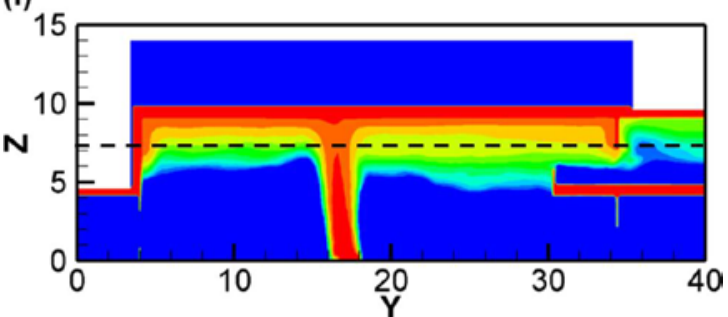

(h)

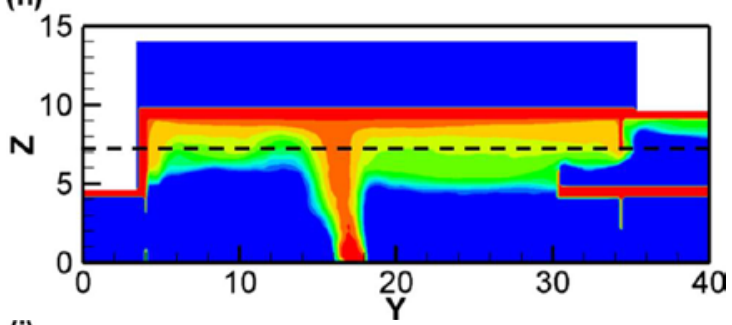

(j)

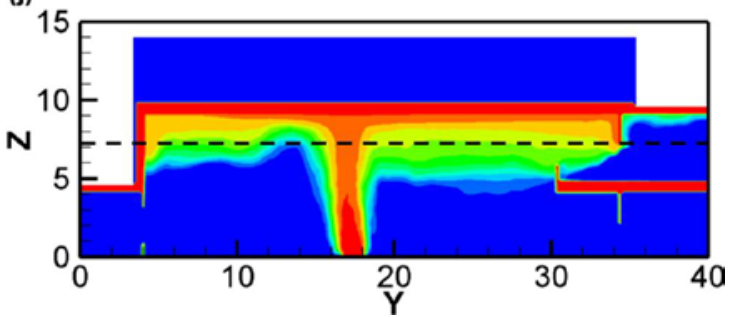

Fig. 4 Visibility at Section AA' under different outdoor temperatures (a) $35^{\circ} \mathrm{C}$;(b) $30^{\circ} \mathrm{C}$;(c) $25^{\circ} \mathrm{C}$;(d) $20^{\circ} \mathrm{C}$;(e) $15^{\circ} \mathrm{C}$;(f) $10^{\circ} \mathrm{C}$;(g) $5^{\circ} \mathrm{C}$;(h) $0^{\circ} \mathrm{C}$;(i) $-5^{\circ} \mathrm{C}$;(j) $-10^{\circ} \mathrm{C}$

In order to study the detailed change of soot densities at different locations of the atrium, three representative points are selected (see Fig. 2) for the analysis. Figure 5 presents the trend of the soot density changes within 350 second of the fire development in the atrium. Point B and $\mathrm{C}$ are $2.2 \mathrm{~m}$ above the first floor. Point $\mathrm{D}$ is $2.2 \mathrm{~m}$ above the second floor. At the lower level of the atrium (Points B and C), it indicates that the change of soot density is not significant within 200 second. After 300 second, soot density becomes invariable at the outdoor temperature of $20^{\circ} \mathrm{C}$ or higher. With the 
decrease of outdoor temperature, the soot density still becomes larger after fire size reaches 4MW, i.e., the fire-induced smoke continually accumulates in the atrium after 300 seconds. At such situation, the natural smoke control strategy already loses the effectiveness. It clearly shows that soot density decreases with the increase of outdoor temperature.
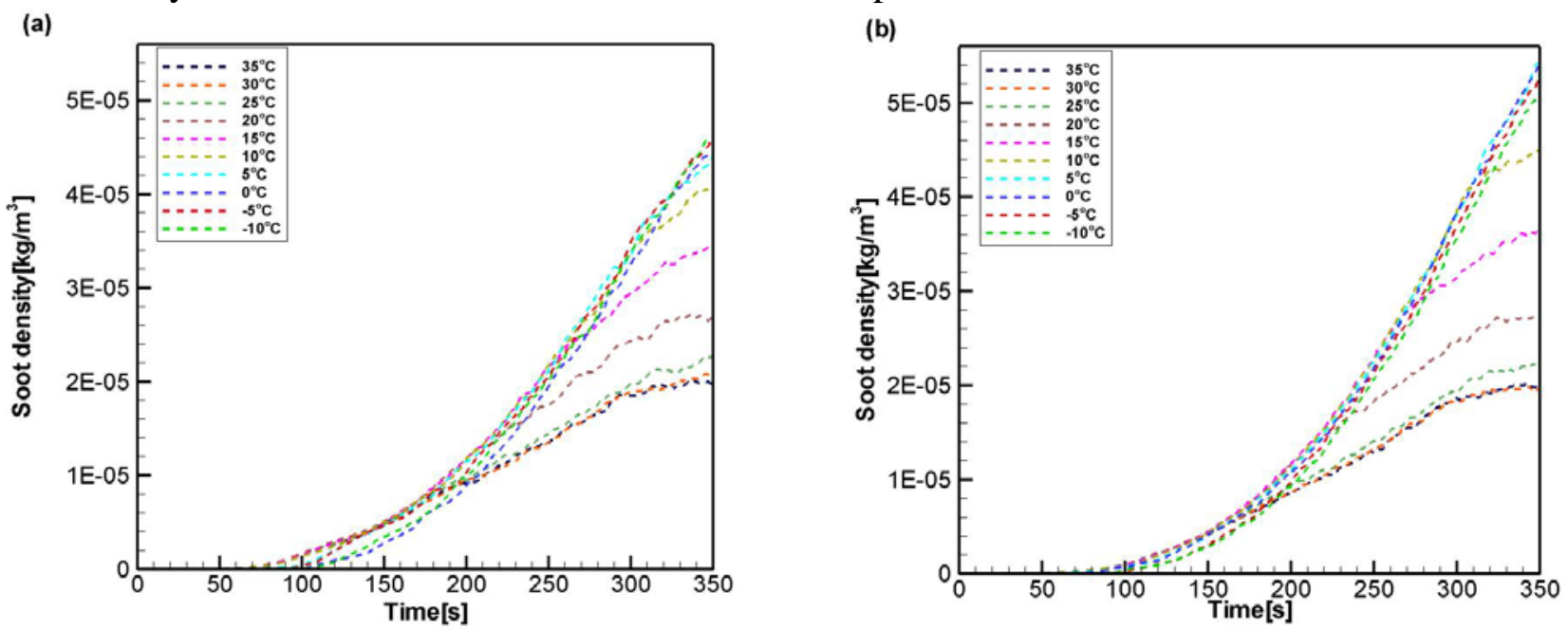

Fig. 5 Comparison of the soot density at (a) Point B; (b) Point C

The temperature contours at Section AA' are presented in Figure 6. The dash line is $2.2 \mathrm{~m}$ smoke clear height above the second floor and is used to evaluate the temperature criteria of the tenable environment [16]. It is shown that the temperature below the smoke clear height is less than $60^{\circ} \mathrm{C}$ and satisfies the tenable environment requirement.

(a)

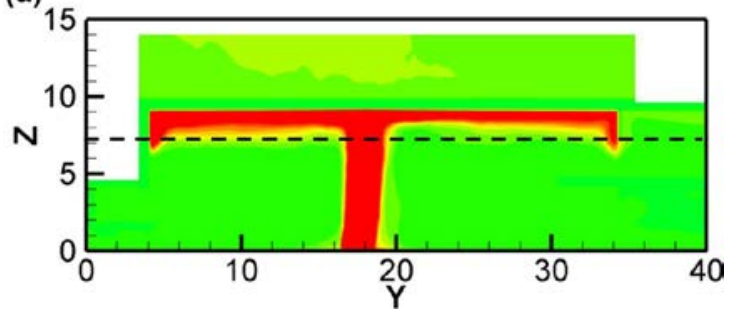

(c)

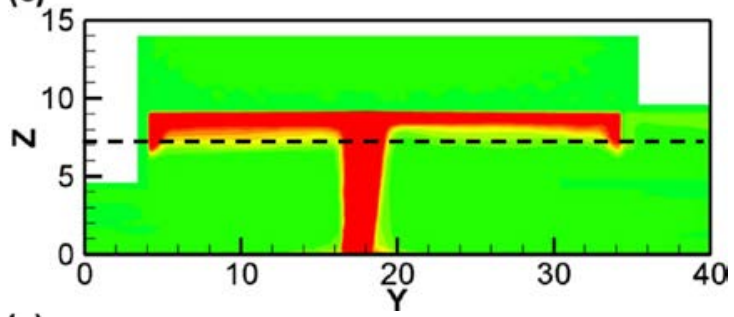

(e)

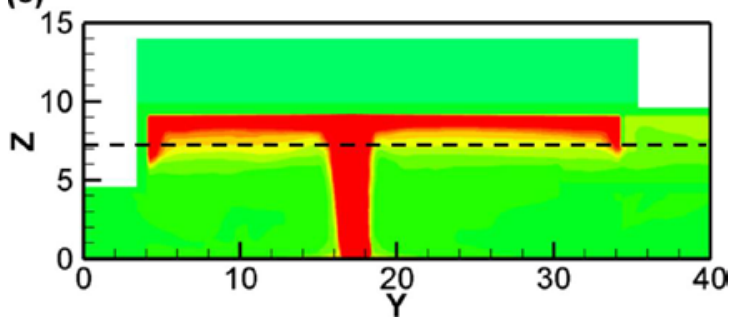

(b)

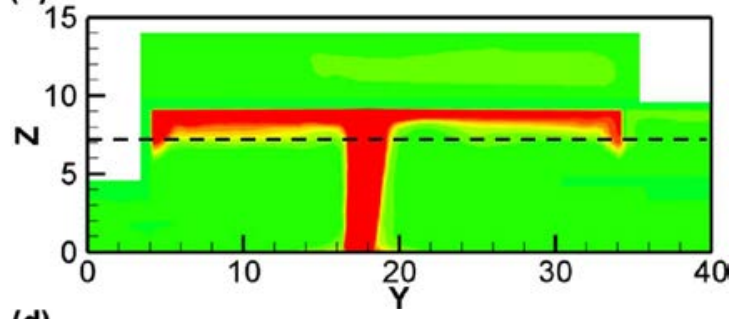

(d)
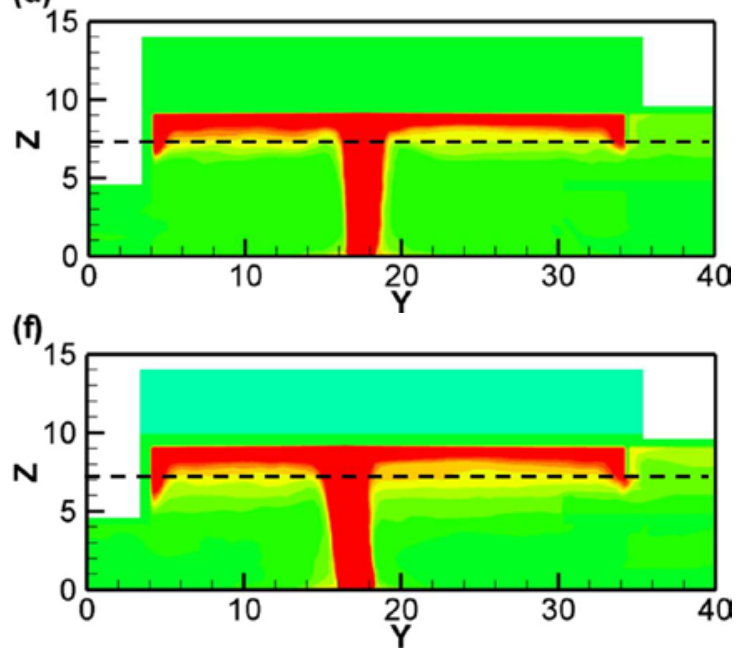

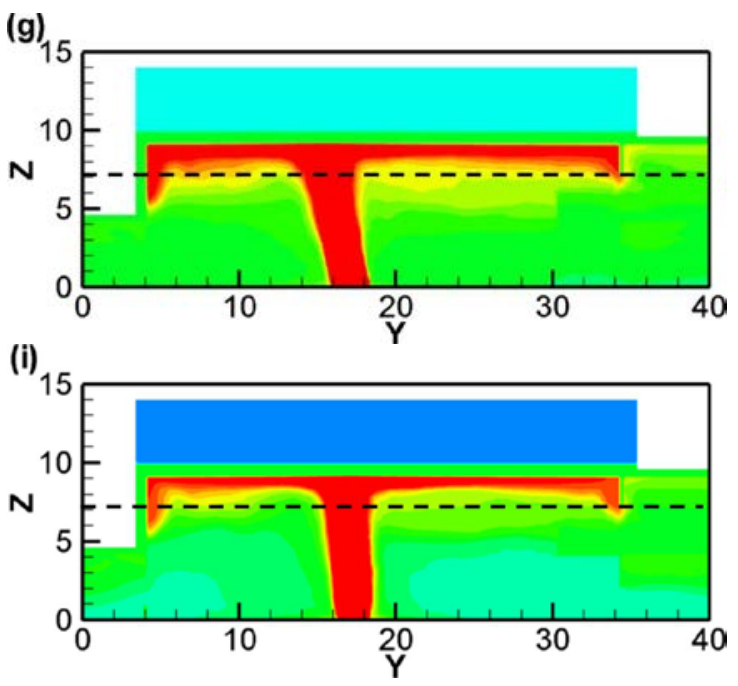

Fig. 6 Temperature profiles at Section AA' under different outdoor temperatures

(a) $35^{\circ} \mathrm{C}$;(b) $30^{\circ} \mathrm{C}$;(c) $25^{\circ} \mathrm{C}$;(d) $20^{\circ} \mathrm{C}$;(e) $15^{\circ} \mathrm{C}$;(f) $10^{\circ} \mathrm{C}$;(g) $5^{\circ} \mathrm{C}$;(h) $0^{\circ} \mathrm{C}$;(i) $-5^{\circ} \mathrm{C}$;(j) $-10^{\circ} \mathrm{C}$
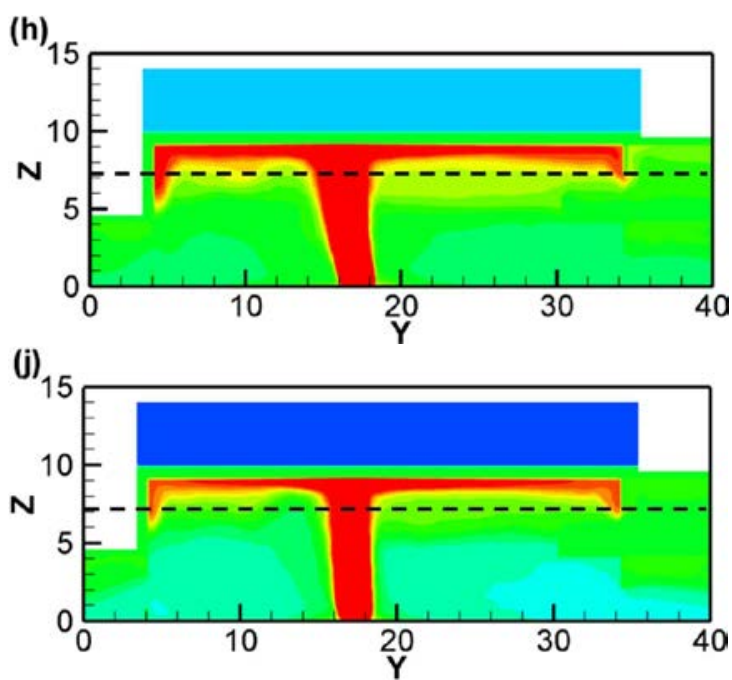

\section{Conclusion}

Effects of outdoor temperature on the natural smoke control strategy in an atrium are studied in this paper. The CFD code of FDS is adopted for the numerical simulation and the results show that the outdoor temperature can significantly influence the development of fire-induced smoke in an atrium when the natural smoke control strategy is adopted. With the decrease of outdoor temperature, the situation worsens in the atrium as the fire-induced smoke cannot be fully driven out by the buoyancy force. The natural smoke control strategy loses the effectiveness originally expected by designers and may results in huge casualties and property loss.

\section{Acknowledgement}

The authors would like to acknowledge the financial support of the funded project of National Natural Science Foundation under Grant No.61376028 and the funded project of Shanghai Science and Commission under Grant No.13111104600.

\section{References}

[1]R. Besserre, P. Delort, Recent studies prove that the main cause of death during urban fires is poisoning by smoke, Urgences Medicales 16 (1997) 77-80.

[2] G.V. Hadjisophocleous, G. Lougheed, Experimental and numerical study of smoke conditions in an atrium with mechanical exhaust, International Journal on Engineering Performance-Based Fire Codes 1 (3) (1999) 183-187.

[3] M.Y.L. Chew, P.H. Liew, Smoke movement in atrium buildings, International Journal on Engineering Performance-Based Fire Codes 2 (2) (2000) 68-76.

[4] W.K. Chow, J. Li, Simulation on natural smoke filling in atrium with a balcony spill plume, J. Fire Sci. 19 (4) (2001) 258-283.

[5] C. Chang, D. Banks, R.N. Meroney, Computational fluid dynamics simulation of the progress of fire smoke in large space, building atria. Tamkang Journal of Science and Engineering 6 (3) (2003) 151-158.

[6]L. Yi, W.K. Chow, Y.Z. Li, R. Huo, A simple two-layer zone model on mechanical exhaust in an atrium, Build. Environ. 40 (7) (2005) 869-880.

[7] C.L. Shi, W.Z. Lu, W.K. Chow, R. Huo, An investigation on spill plume development and 
natural filling in large full-scale atrium under retail shop fire, Int. J. of Heat Mass Tran. 50 (3-4) (2007) 513-529.

[8] Y. Ji, M.J. Cook, V. Hanby, CFD modelling of natural displacement ventilation in an enclosure connected to an atrium, Build. Environ. 42 (3) (2007) 1158-1172.

[9] W.K. Chow, J. Li, On the bidirectional flow across an atrium ceiling vent, Build. and Environ. 46 (12) (2011) 2598-2602.

[10] H.R. Wang, W.L. Dong, D. Liang, Performance-based design of smoke control and evacuation in a building atrium, Procedia Engineering 11 (2011) 431-436.

[11] N. Tilley, B. Merci, Numerical study of smoke extraction for adhered spill plumes in atria: Impact of extraction rate and geometrical parameters, Fire Saf. J. 55 (2013) 106-115.

[12] J.B. Xu, C. Zhang, J.F. Zhao, Q.Q. Chen, J.B. Wu, The study on influence factors of the mechanical smoke evacuation system in atrium buildings, Procedia Engineering 52 (2013) 508-513.

[13] T.X. Qin, Y.C. Guo, C.K. Chan, W.L. Lin, Numerical simulation of the spread of smoke in an atrium under fire scenario, Build. Environ. 44 (1) (2009) 56-65.

[14] C. Gutiérrez-Montes, E. Sanmiguel-Rojas, A.Viedma, Influence of different make-up air configurations on the fire-induced conditions in an atrium, Build. Environ. 45 (11) (2010) 2458-2472.

[15] R. Gao, A.G. Li, X.P. Hao, W.J. Lei, Y.J. Zhao, B.S. Deng, Fire-induced smoke control via hybrid ventilation in a huge transit terminal subway station, Energ. Buildings 45 (2012) 280-289.

[16] National Fire Protection Association, Technical Committee on Road Tunnel and Highway Fire Protection. NFPA 502, Standard for Road Tunnels, Bridges, and Other Limited Access Highways. NFPA 2010.

[17] K. McGrattan, G.P. Forney, Fire Dynamics Simulator (Version 5), User’s Guide. NIST special publication. 1019 (2008) 1-186.

[18] S.B. Pope, Ten questions concerning the large-eddy simulation of turbulent flows, New J. Phys. 6 (35) (2004) 1-24.

[19] J. Smagorinsky, General circulation experiments with the primitive equations I. The basic experiment, Mon. Weather Rev. 91 (3) (1963) 99-164.

[20] W. Zhang, N. Ryder, R.J. Roby, D.Carpenter, Modeling of the combustion in compartment fires using large eddy simulation approach, In Proceedings of the 2001 Fall Technical Meeting.

[21] W. Zhang, A. Hamer, M. Klassen, D. Carpenter, R. Roby, Turbulence statistics in a fire room model by large eddy simulation, Fire Saf. J. 37 (8) (2002) 721-752.

[22] L.H. Hu, J.W. Zhou, R. Huo, W. Peng, H.B.Wang, Confinement of fire-induced smoke and carbon monoxide transportation by air curtain in channels, J. Hazard. Mater. 156 (1-3) (2008) 327-334. 